V Congresso Brasileiro de Informática na Educação (CBIE 2016)

Anais do XXII Workshop de Informática na Escola (WIE 2016)

\title{
Histórias em quadrinhos digitais: trabalho interdisciplinar promovendo autoria na EJA
}

\author{
Rossana Andrade ${ }^{1}$, Jessica Balbinot Plá ${ }^{1}$, Joice Balbuena Iribarem ${ }^{1}, C_{e v i}$ Rapkiewicz ${ }^{1}$, \\ Juçara Benvenuti', \\ Colégio de Aplicação da UFRGS \\ rohssana@gmail.com, jessicab.pla@gmail.com, joice.balbuena@gmail.com, \\ clevieufrgs.br, benvenutieufrgs.br
}

\begin{abstract}
Resumo. Um dos aspectos importantes da sociedade digital é propiciar aos alunos a oportunidade de serem autores e não meros consumidores de conteúdo. Visando incentivar os alunos da EJA a serem autores, buscamos uma ação integrada entre Cultura Digital e Língua Portuguesa e Literatura durante dois semestres, envolvendo duas turmas de ensino médio desenvolvendo tirinhas digitais. Os estudantes tiveram oportunidade de letramento a partir da linguagem icônica presente nos quadrinhos, aproveitando ao mesmo tempo o aspecto lúdico que estes apresentam tornando-se autores no mundo digital. Foi possível constatar o alto potencial do uso de desenvolvimento de tirinhas digitais no processo de letramento e autoria entre alunos da EJA, público este muitas vezes esquecido nos projetos educativos.
\end{abstract}

Palavras-chave: história em quadrinhos, Língua Portuguesa, EJA, autoria

Abstract. One of the important aspects of digital society is to give students the opportunity to be authors and not merely consumers of content. Aiming to encourage EJA students to be authors, we seek an integrated action between Digital Culture and Portuguese Language and Literature during two semesters, involving two high school groups developing digital comic strips. The students experienced literacy opportunity because of the iconic language presented in the comics, enjoying at the same time the playful aspect of the comics and becoming authors in the digital world. It was possible to evidence the high potential of using the development of digital comic strips in the EJA students' process of literacy and authorhip, a public which is often forgotten in educational projects.

Key-words: comics, Portuguese, digital, EJA, autorship

\section{Introdução}

As Histórias em Quadrinhos (HQs) são um gênero textual com grande potencial para serem utilizadas pedagogicamente, por unirem a linguagem icônica com a linguagem verbal constituindo assim um gênero muito particular - e por proporcionarem ludicidade para a realização de várias atividades e propostas diferentes em diversos níveis e modalidades de ensino. Os textos com que os estudantes entram em contato atualmente são cada vez menos constituídos apenas de linguagem escrita, e cada vez mais integrados com imagens. Justamente devido a isso, exames como o ENEM passaram a adotar gêneros textuais que incluem gráficos e imagens, para avaliar as habilidades dos estudantes de interpretação de texto e imagem. Nesse paradigma cotidiano e educacional, portanto, as HQs podem se mostrar um excelente meio de letramento na leitura, interpretação e significação desses textos multimodais. 
V Congresso Brasileiro de Informática na Educação (CBIE 2016)

Anais do XXII Workshop de Informática na Escola (WIE 2016)

Dado esse contexto, as tecnologias de informação e comunicação (TIC) representam tanto um meio de se ter acesso aos quadrinhos - com o subgênero webcomic tendo suas próprias particularidades (SANTOS, CORREAA, TOMÉ, 2012) -, quanto de proporcionar a pessoas que não têm as habilidades artísticas de outra forma necessárias a possibilidade de criar suas HQs ou, de forma inicial, tirinhas digitais que possam mais tarde serem ampliadas para histórias mais completas. Da mesma forma, atividades de criação de quadrinhos digitais podem proporcionar a oportunidade de desenvolver habilidades relacionadas às TIC, se levarmos em consideração a substituição das habilidades artísticas de criação de quadrinhos (EISNER apud PATO, 2007) pelas mencionadas anteriormente. Isso sugere que tirinhas digitais também teriam um potencial próprio diferenciado.

Uma revisão bibliográfica recente, no entanto, sobre o uso de HQ integrado com TIC sugere que esse potencial não vem sendo aproveitado (PLÁ e RAPKIEWICZ, 2015). Conforme apontam as autoras, ainda que os Parâmetros Curriculares Nacionais (PCN) considerem as HQ um gênero adequado para ser trabalhado em sala de aula, e o Programa Nacional Biblioteca na Escola (PNBE) incentive e aumente o espaço destinado aos quadrinhos nas escolas brasileiras, isso, contudo, não é garantia de que o potencial desse gênero seja completamente ou adequadamente explorado.

Uma análise realizada na pesquisa TIC e Educação de 2014 também indica pouco espaço na sala de aula para atividades que poderiam englobar as histórias em quadrinhos em conjunto com as TIC. Além disso, ao buscar por termos relacionados a histórias em quadrinhos em quatro publicações brasileiras e uma internacional de informática na educação do período de 2009 a 2014, Plá e Rapkiewicz (2015) encontraram apenas sete artigos relacionados ao tema, o que já indica um baixo interesse na área de pesquisa.

Com o intuito de ampliar a literatura desta área apresentamos esse artigo sobre um projeto criado no Colégio de Aplicação da UFRGS (CAP UFRGS) que busca investigar o uso de HQ digitais no processo de fomento de autoria de alunos de ensino médio na modalidade EJA. Este artigo analisa os dois primeiros anos do projeto (2014 e 2015) período no qual foi proposto que os alunos de segundo ano interagissem com as Histórias em Quadrinhos num processo interdisciplinar com Língua Portuguesa e Cultura Digital. O presente artigo está dividido em cinco seções: essa introdução, que contextualiza o projeto; referencial teórico, que mostra as bases pedagógicas para a criação deste projeto, buscando destacar aspectos da Educação de Jovens e Adultos (EJA), bem como a possibilidade de autoria digital nessa modalidade de educação; metodologia, que apresenta o projeto e o modo como foi realizado em sala de aula, tanto do ponto de vista da autoria digital quanto do desenvolvimento de aspectos da Língua Portuguesa associados ao gênero textual HQ; e, alguns resultados preliminares, onde são comentadas algumas tirinhas mostrando o potencial de autoria. Por fim são apresentadas algumas considerações a partir da análise dos resultados parciais, indicando potencialidades e fragilidades do projeto.

\section{EJA, letramento e autoria}

A EJA é uma modalidade prevista na Lei de Diretrizes e Bases (lei 9394/96), a qual destaca, no seu artigo 37: "A educação de jovens e adultos será destinada àqueles que não tiveram acesso ou continuidade de estudos no ensino fundamental e médio na idade própria" (BRASIL, 1996, p.15). Nessa modalidade, portanto, encontram-se sujeitos que construíram suas vidas sem concluir o currículo escolar básico, porém desenvolveram as mais variadas formas de 
V Congresso Brasileiro de Informática na Educação (CBIE 2016)

Anais do XXII Workshop de Informática na Escola (WIE 2016)

conhecimento. Não se trata meramente de reposição de escolaridade perdida (DI PIERRO, JOIA e RIBEIRO, 2001), mas da percepção de um processo de ensino e aprendizagem que ocorre ao longo da vida. Trata-se de uma modalidade que atende a um público com características específicas, com saberes adquiridos no âmbito da família, do trabalho e demais esferas de socialização. Ou seja, muitas vivências adquiridas fora do espaço escolar:

No passado como no presente, a educação de jovens e adultos sempre compreendeu um
conjunto muito diverso de processos e práticas formais e informais relacionadas à
aquisição ou ampliação de conhecimentos básicos, de competências técnicas e
profissionais ou de habilidades socioculturais. Muitos desses processos se desenvolvem
de modo mais ou menos sistemático fora de ambientes escolares, realizando-se na
família, nos locais de trabalho, nos espaços de convívio socio cultural e lazer, nas
instituições religiosas e, nos dias atuais, também com o concurso dos meios de
informação e comunicação à distância. (HADDAD;DIPIERRO2000, p.108)

Por sua constituição o público da EJA é bastante heterogêneo. Sant'Anna e Stramare (2001) os caracterizam como jovens e adultos em geral trabalhadores. Mesmo tendo passado por um processo de exclusão na idade de escolarização regular são críticos, questionadores e com muita vontade de aprender. Portanto, a especificidade desta modalidade de ensino ultrapassa o limite da escolarização no seu sentido estrito, razão pela qual oportunizar aos discentes da EJA possibilidade de complementar e continuar sua formação torna-se pertinente.

Segundo Benvenuti (2012, p.168) "a escola tradicionalmente tem sido responsabilizada pelo acesso a tecnologia da leitura e da escrita e pela aprendizagem das habilidades e atitudes necessárias para seu uso nas práticas sociais" (2012), isto é, o letramento. Para atingir essa meta os alunos precisam ser participantes ativos das aulas, produzindo textos, fazendo correções e leituras.

Práticas sociais de leitura e escrita, na assim chamada Sociedade da Informação, estão asociada ao uso da web como plataforma. A visão da Web 2.0, termo criado em 2004 durante uma seção de brainstorming entre O'Reilly (2005) e a MediaLive International, está fortemente associada com as possibilidades dos próprios usuários e não somente especialistas em TIC ou em comunicação poderem produzir conteúdos.

Oportunizar que alunos de escolas públicas possam ser prosumidores, isto é, ir além do papel de consumidores e tornarem-se também produtores. Este termo, cunhado por Tofler em 2007 em seu livro A Terceira Onda, encontrou uma nova versão no mundo on-line. Trata-se do consumidor que possui mais poder, que emite opiniões, produz informações sobre o que consome e influencia outros consumidores. No âmbito educacional, podemos entender o prosumidor como alguém que não somente busca informações e conhecimento na Internet, mas também as produz. Essas práticas, no entanto, ainda não são muito comuns, pelo menos é o que sugerem os dados da pesquisa quantitativa TIC Educação desenvolvida pelo CETIC (Centro Regional de Estudos para o Desenvolvimento da Sociedade da Informação) do Comitê Gestor da Internet no Brasil (CGI.br) ao indicar que, em 2013, 96\% dos professores consultados utilizavam recursos educacionais digitais para o preparo de aulas ou atividades com os alunos, embora somente $21 \%$ destes publicassem ou compartilhassem suas próprias produções. O que dirá, então, em relação aos alunos em práticas pedagógicas que estimulem a autoria na web?

Como uma forma de estimular a escrita e a leitura na EJA, apresentamos o conceito de História em quadrinhos (HQ) que é uma narrativa visual que, normalmente, expressa a língua oral e apresenta um enredo rápido, empregando somente imagem ou associando palavra e imagem. Destacamos que é de fundamental importância que haja uma efetiva interação entre o 
V Congresso Brasileiro de Informática na Educação (CBIE 2016)

Anais do XXII Workshop de Informática na Escola (WIE 2016)

leitor e o discurso, associando-o a elementos icônicos (imagens) e ao texto (elementos linguísticos), por se tratar de uma comunicação mais imediata, da forma que geralmente é cobrada em exames como o Exame Nacional do Ensino Médio. Uma das formas possíveis de estimular a autoria na web está na oferta de serviços online para produção de tirinhas ou histórias, alguns dos quais analisados por Santos, Rapkiewicz e Santos (2014).

Os quadrinhos estão por toda a parte, pois constituem um gênero textual, que diz respeito à diversidade de estruturas de textos, com características, marcas, funções especificas para cada situação do ato comunicativo. Também servem para entreter, podem veicular uma mensagem instrucional - podem ser usados para uma campanha de economia de água, para alertar sobre riscos de doenças ou para transmitir informativos de trânsito, por exemplo e isso também foi salientado nas aulas teóricas de HQ. Desta forma procuramos mostrar aos alunos que o uso das histórias em quadrinhos pode ser inserido em diversos contextos das vidas deles.

\section{Metodologia}

Elaboramos uma proposta de estratégia pedagógica para trabalhar nas disciplinas de Língua Portuguesa e Literatura e Cultura Digital na Educação de Jovens e Adultos (EJA), que possui características particulares que a distinguem e a destacam das modalidades regulares de ensino.

Levando em consideração as particularidades do público da EJA, e as necessidades que suscitam em um contexto midiático/informacional que mencionamos anteriormente, a proposta pedagógica de uso das histórias em quadrinhos que desenvolvemos tem como objetivo principal proporcionar aos estudantes dessa modalidade de ensino uma oportunidade de letramento intersemiótico a partir da linguagem icônica presente nos quadrinhos, aproveitando ao mesmo tempo o aspecto lúdico que estes apresentam. Buscamos oportunizar, pois, que exerçam o papel de prosumidores.

Para que sejam prosumidores nesse contexto é necessário trabalhar habilidades tanto de leitura quanto de escrita desse gênero textual, de forma que os objetivos da proposta são:

HQs.

1) Reconhecer o significado e a interação entre todos esses elementos que compõe o

2) Resgatar e aprimorar a habilidade de interpretar e significar a linguagem verbal e icônica.

3) Desenvolver a habilidade de interpretar e significar as diferentes linguagens presentes.

Para alcançar esses objetivos será necessário trabalhar com os alunos os seguintes itens:

- Os próprios quadrinhos, seu tamanho e disposição;

- Os diferentes balões e caixas de diálogo/narração, bem como outras maneiras de indicar visualmente a ocorrência de linguagem verbal (falas, pensamentos, etc.);

- A expressão facial e/ou corporal dos personagens, bem como a disposição dos personagens na cena;

- O plano de fundo e o ambiente desenhado na cena;

- Os objetos em interação e/ou em foco na cena. 
V Congresso Brasileiro de Informática na Educação (CBIE 2016)

Anais do XXII Workshop de Informática na Escola (WIE 2016)

Para viabilizar o projeto foram promovidos encontros dos estudantes com o gênero Histórias em Quadrinhos, de forma gradual que culminou em uma produção individual realizada, com uso das TIC. Ao final as produções foram organizadas num e-book.

Assim, no inicio dos trabalhos os estudantes foram apresentados a uma tirinha simples sem falas, com todos os quadrinhos do mesmo tamanho e focada nos personagens. É importante desde esta fase ressaltar e demonstrar que a imagem narra tanto quanto o texto escrito, e que, por isso, não deve servir apenas como ilustração, repetindo o que já está dito no texto. Essa noção foi trazida novamente de maneira recorrente ao longo das atividades. Após apresentar a tirinha, o(a) professor(a) deve questionar os aprendizes com algumas perguntas, de modo a construir as respostas a partir de seu conhecimento prévio e do que será introduzido de novo, e gerando discussões para interpretar as tirinhas. A maioria se repetirá ao longo dos diferentes graus, de modo a fixar essas noções, ou por serem perguntas fundamentais de interpretação.

- Qual a situação representada na tirinha? (pergunta de interpretação)

- Qual a impressão/efeito que causa no leitor? (surpresa, encanto, graça, etc.)

- Seria possível causar o mesmo efeito se essa situação fosse descrita de forma escrita? (esta pergunta serve para demonstrar a diferença entre o texto intersemiótico e o texto escrito)

- O que está presente na cena? (Personagens - objetos)

- Como a passagem do tempo é representada? (para demonstrar uma das funções dos quadrinhos, de delimitação do espaço e do tempo)

O segundo momento consiste em mostrar aos alunos uma tirinha simples com falas, com personagens muito expressivos. O conteúdo das falas em si não é tão importante quanto sua coerência com as expressões dos personagens, pois isso é o que será explorado. As perguntas básicas do grau 1 devem ser repetidas, com a adição de "Qual a importância da interação entre o que é dito e o que vemos?" e o restante se decorre como uma atividade expositória por parte do professor, explorando os balões da tirinha para mostrar os diferentes tipos de balões mais recorrentes em quadrinhos (de fala, pensamento, exclamação, quadro de narração); a relação dos balões com o conteúdo semântico da fala, e por consequência com a expressão do personagem. Por exemplo, um personagem que esteja gritando de dor terá sua fala representada por um balão de exclamação e sua expressão será condizente. É importante demonstrar também que às vezes uma expressão estática ou incoerente com o que o personagem está dizendo pode ser proposital para criar um determinado efeito estético; isso é algo que pode ser explorado pelo(a) professor(a).

$\mathrm{Na}$ terceira etapa, é exposta aos alunos uma tirinha parecida com a primeira, mas cujo efeito estético depreenda-se principalmente de um objeto em interação com algum personagem ou que esteja em foco na cena principal, como no exemplo desta tirinha de Laerte (figura 1) e da tirinha Armandinho (figura 2): 


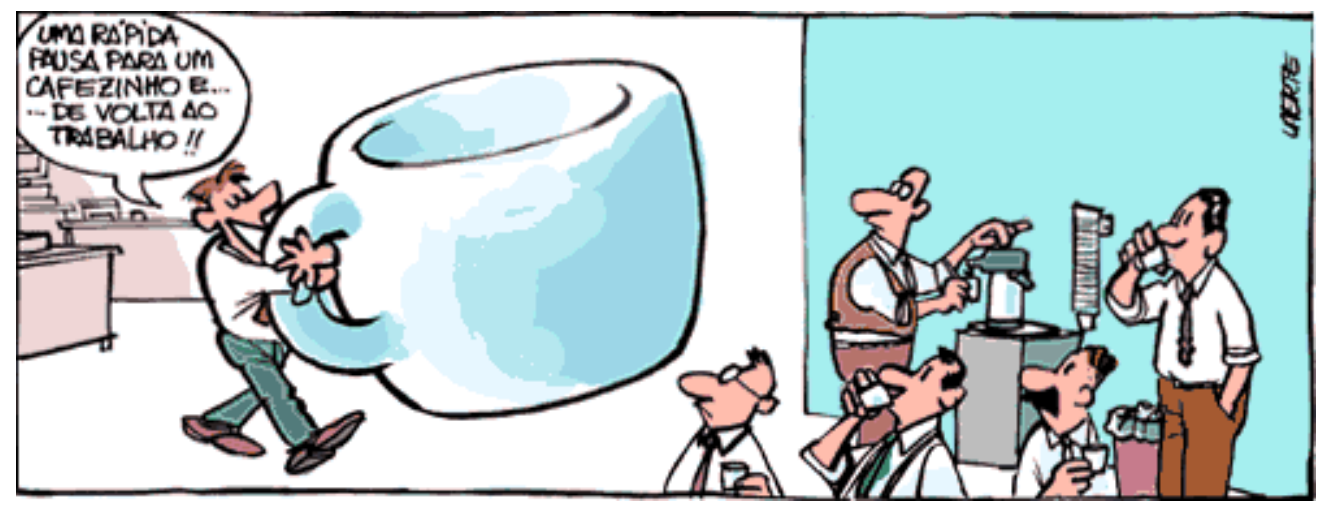

Figura 1: Tirinha com efeito da interação de um personagem interagindo com um objeto

Essa fase é importante porque é possível notar que muitas vezes em suas produções com histórias em quadrinhos os aprendizes costumam ignorar a interação dos personagens com objetos da cena e do ambiente, deixando os personagens e objetos estáticos e ignorando oportunidades de criar um plano de significação mais amplo, como acontece na tirinha acima. A pergunta "Qual a importância da apresentação e da interação dos objetos nesta tirinha?" deve ser trazida à discussão junto com as anteriores.
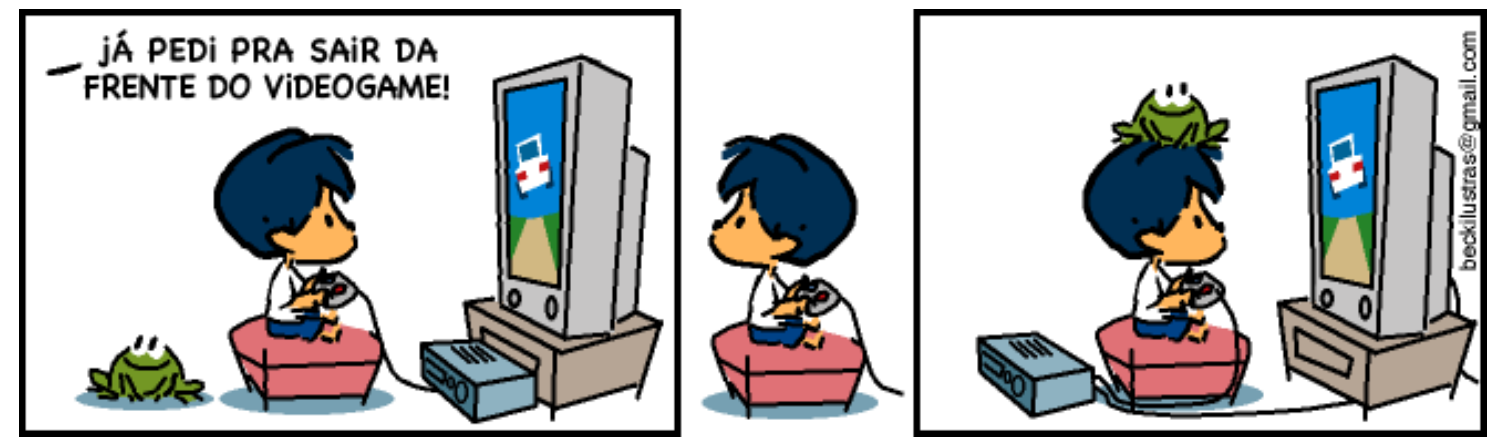

Figura 2: Tirinha Armandinho - efeito causado pela movimentação de um objeto

O número de tirinhas trabalhadas e a extensão da discussão pode variar de acordo com o que o(a) professor(a) julgar necessário para as particularidades de cada turma, já que o que está aqui proposto seria um número mínimo para cada momento; o recomendável seria trabalhar duas tirinhas para cada um. Seria possível, também, imaginar um quarto momento, dentro das possibilidades de cada turma, trabalhando um trecho de capítulo de uma graphic novel, subgênero de história em quadrinhos, que agruparia todos os elementos estudados em um texto mais complexo.

A atividade final individual dos alunos consiste em elaborar duas tirinhas digitais a partir de um único roteiro, de tema livre à escolha do que estiver sendo abordado em aula pelo(a) professor(a). Primeiro, eles devem produzir um roteiro simples com uma contextualização, lista de personagens, indicação dos quadrinhos e falas dos personagens. Efeitos especiais e descrições detalhadas da cena não são necessários, apenas um contexto inicial. Feito isto, o(a) professor(a) expõe o objetivo da atividade: produzir duas tirinhas a partir do mesmo roteiro, mudando apenas elementos visuais como objetos e a interação entre si e com os personagens, expressões balões, que personagem diz qual fala (apenas uma fala pode ser mudada, para que esse recurso não seja abusado e isso se torne uma mudança textual), etc. Recomenda-se produzir duas tirinhas de exemplo de antemão para que os alunos não se confundam com a tarefa, que não é tão difícil 
V Congresso Brasileiro de Informática na Educação (CBIE 2016)

Anais do XXII Workshop de Informática na Escola (WIE 2016)

quanto parece inicialmente. Uma vez conhecedores do verdadeiro objetivo, os alunos devem, então, registrar em seu roteiro que mudança farão. Depois, utilizando o serviço online para edição de HQ Pixton - escolhido por ter opção gratuita (ainda que com algumas limitações), oferecer uma interface intuitiva em português e ser multiplataforma, conforme apontado por Santos, Rapkiewicz e Santos em 2014.

Finalmente, conforme já apontado, as tirinhas foram organizadas em um e-book da turma.

\section{Alguns resultados}

Após o termino das atividades foi elaborada uma pesquisa com os alunos sobre o uso de HQ no âmbito escolar na EJA. Essa pesquisa foi elaborada baseada em diversas questões, das quais destacamos a seguinte: "Qual a sua percepção da atividade integrada entre Língua Portuguesa e Cultura Digital envolvendo histórias em quadrinhos? Procure refletir sobre a relevância dessa atividade para você. Destaque partes importantes do processo." Analisadas as respostas dos participantes dessa atividade que tinham idade entre 18 a 62 anos, percebemos que as respostas foram bastante variadas. Destacamos algumas, sem identificar diretamente os alunos, buscando apontar que a amplitude de idade na turma (18 a 62 anos), ainda que tenha tido diferentes graus de dificuldade no que concerne ao domínio do serviço Pixton não impede a autoria:

"É uma atividade boa, pois nos faz refletir e aperfeiçoar nosso senso crítico e o expressar de uma forma diferente que são as histórias em quadrinhos." R, 18 anos.

"Na minha percepção, a cultura digital envolvendo quadrinhos foi muito boa e de fácil aprendizagem" E, 37 anos.

"É novidade! Nunca utilizei nem pratiquei na cultura digital em quadrinhos, somente o editor de texto. Tudo que é novo, quando se tem oportunidade, é importante a prática." $\mathrm{V}, 62$ anos.

Para exemplificar apresentamos três tirinhas, com comentários:

\section{Q Lâmpadas com sensor}

(c) Wednesday November 19, 2014 7 visualizações $\mid 0$ comentários
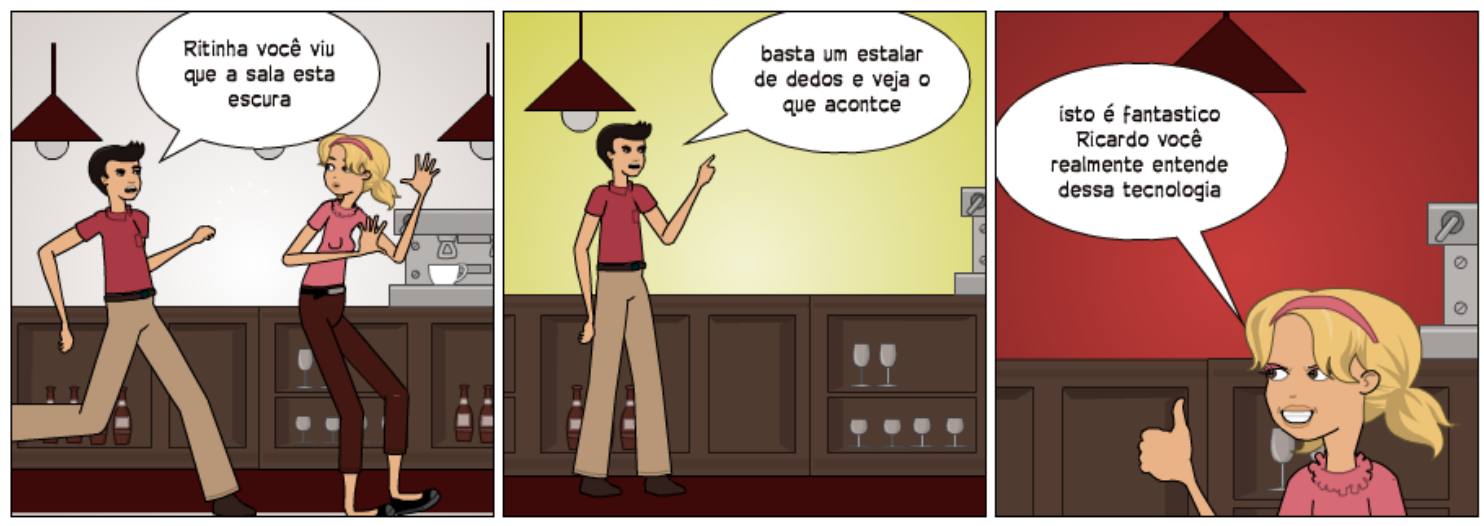

Figura 3 Tirinha de aluno, 62 anos

Nessa tirinha (Figura 3) o aluno fez um bom uso de todos os elementos trabalhados em sala de aula. A história em quadrinho apresenta cenário de acordo com o tema da história, fala dos 
V Congresso Brasileiro de Informática na Educação (CBIE 2016)

Anais do XXII Workshop de Informática na Escola (WIE 2016)

personagens, movimento dos membros dos personagens, expressão facial condizente com a fala, entre outros elementos.

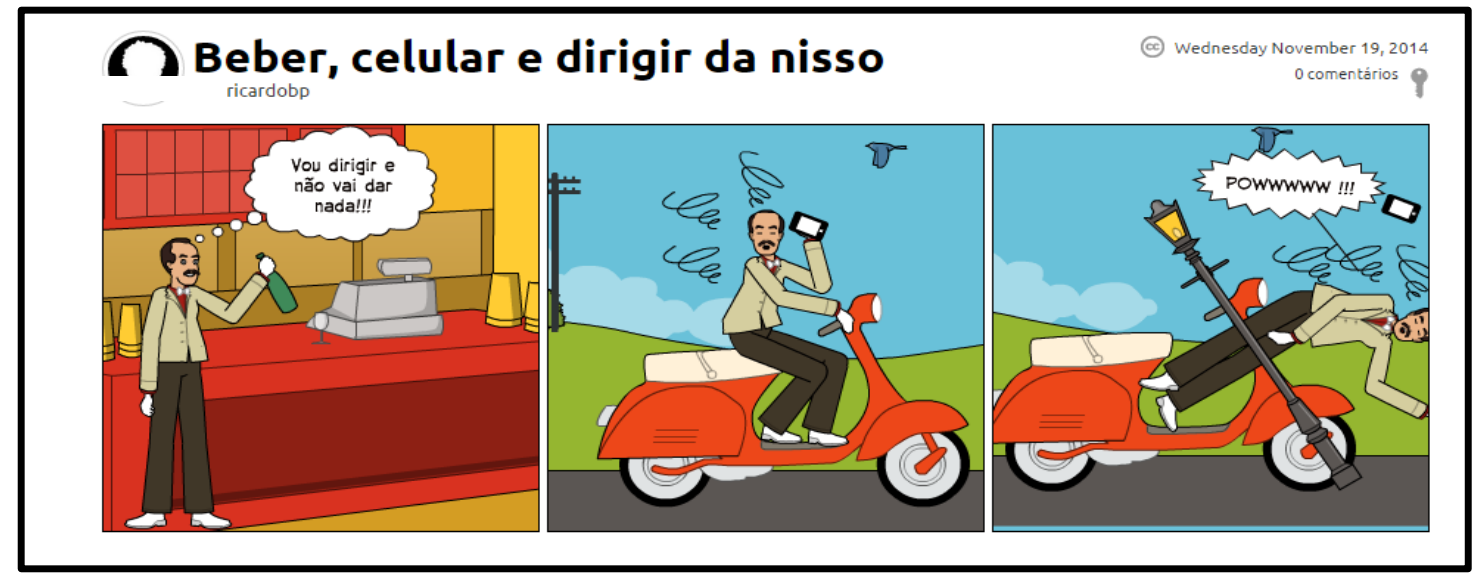

Figura 4 Tirinha de aluno, 40 anos

Na Figura 4 apresentamos uma tirinha em que o aluno além de fazer um bom uso dos elementos como uso de onomatopeia, balão de pensamento, cenário variado condizente com o contexto, movimento do personagem, inserção de objetos na cena, a HQ também fez uma critica social.

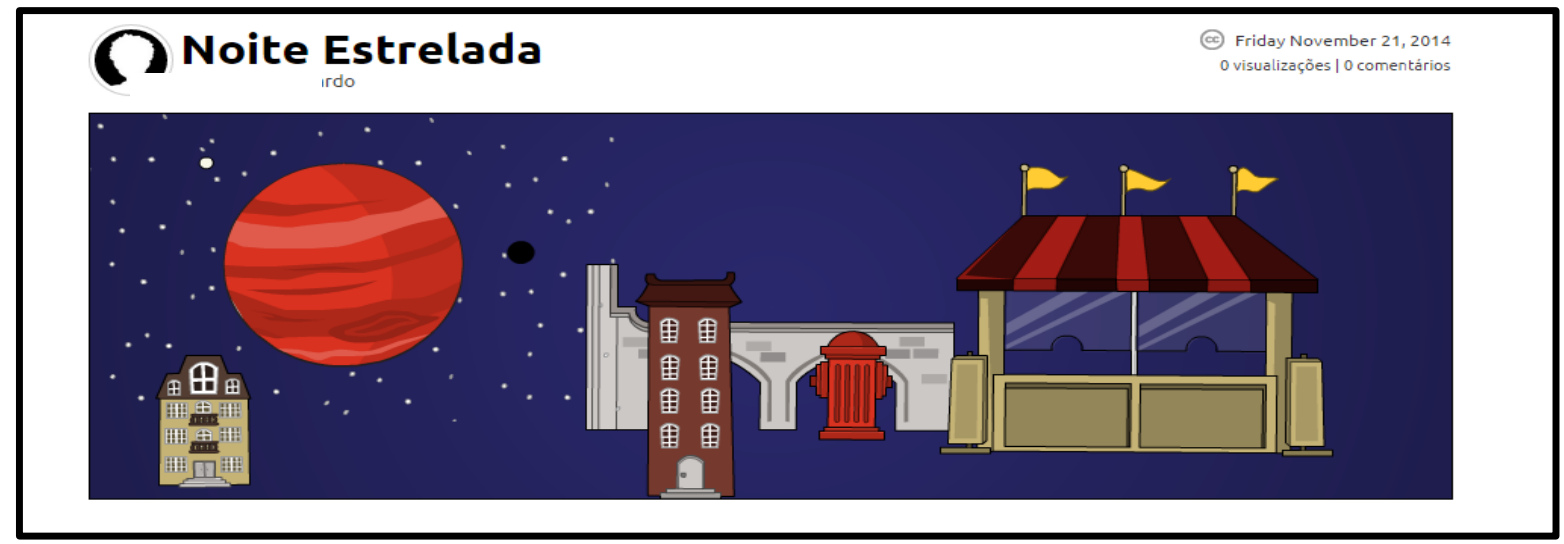

Figura 5 Tirinha de aluno, 32 anos

Na tirinha na Figura 5 percebemos que o aluno não fez um bom uso do cenário, colocou objetos aleatórios e não fez bom uso das dimensões do objetos, por exemplo, o hidrante do tamanho de uma ponte. Também não fez uso de personagem e nem de fala. Isso mostra que nem sempre atingimos o objetivo com todos os alunos. Ha diversos fatores que levam o aluno a não atingir o objetivo da ação pedagógica, (que é que o aluno produza uma tirinha com fala, personagem e interação com o cenário) por exemplo, a falta de interesse do aluno para com o conteúdo apresentado em sala de aula ou até mesmo a dificuldade com a ferramenta digital. São elementos a serem trabalhados, o que nem sempre é possível quando se tem turmas grandes e ampla heterogeneidade do público atendido, como é o caso na EJA.

\section{Algumas Considerações}

Este artigo pretendeu oferecer não somente uma análise, como também apresentar uma proposta pedagógica colocada em prática durante dois semestres para a EJA a cerca da atividade de 
V Congresso Brasileiro de Informática na Educação (CBIE 2016)

Anais do XXII Workshop de Informática na Escola (WIE 2016)

produção de HQ, buscando a autoria dos alunos. Foi possível perceber uma melhor aceitação da atividade de elaboração dos quadrinhos ao longo do segundo semestre, quando a ação se desenvolveu pela segunda vez. De início os alunos participantes demoraram a compreender o real sentido da elaboração das tirinhas. $\mathrm{O}$ que pretendíamos inicialmente é que o aluno passasse a enxergar-se como autor além de leitor de HQs, ou seja, que além de desenvolver, na disciplina de português, compreensão e entendimento para efetuar com êxito leituras de Histórias em Quadrinhos, também fossem capazes de produzir a sua própria tirinha através de recursos digitas nas aulas de Cultura Digital. O projeto tinha como objetivo apresentar aos alunos uma forma alternativa de interação com a sociedade e o mundo digital, recuperando o hábito de ler histórias em quadrinhos nos alunos mais velhos e despertando maior interesse dos alunos mais novos.

Percebemos que alunos mais jovens tiveram menos dificuldade e maior interesse e consequentemente obtiveram resultados diferenciados na produção de suas tirinhas, por estarem melhor inseridos ao contexto digital ao qual foram apresentados. $\mathrm{O}$ fenômeno da juvenilização da EJA, com alunos cada vez mais jovens nessa modalidade de ensino torna ainda mais importante práticas como a propiciada neste projeto. Em contraponto alunos de uma faixa etária mais alta tiveram maior dificuldade em desenvolver essa atividade, pois além de recuperar o habito da leitura de HQs tiveram também de conhecer e aprender a manusear novas ferramentas digitais, como a plataforma Pixton, o que nem sempre é evidente para imigrantes digitais. Nem por isso deve-se deixar de atentar que autoria, nas faixas etárias mais elevadas, é também elemento de aumento da auto-estima, quando, por exemplo, o aluno de 62 anos apresenta sua tirinha para a neta dizendo "eu também sei fazer coisas de gibis" usando computador. Esse é o verdadeiro sentido da autoria - a apreciação por algum leitor.

Entre as dificuldades encontradas apontamos as variações de versões gratuitas de serviços na web. Restrições as vezes são implementadas durante o próprio desenvolvimento do projeto, limitando escolhas dos alunos provocando desinteresse em algumas situações. $\mathrm{O}$ desenvolvimento de aplicativo ou serviço online por grupos de pesquisa da área de Informática na educação no Brasil que oferecessem funcionalidades semelhantes as plataformas analisadas por Santos, Rapkiewicz e Santos (2014) poderia contribuir para diminuir essas dificuldades.

Também encontramos restrições de computadores nem sempre adequados na esfera pública, o que sugere que o uso de recurso de dispositivos móveis do próprio aluno, cada vez mais comum, possa ser uma alternativa a ser analisada.

\section{REFERÊNCIAS}

BENVENUTI, Juçara. Letramento, Leitura e Literatura no Ensino Médio da Modalidade de Educação de Jovens e Adultos: uma proposta curricular. Volume 1. Tese de Doutorado. Instituto de Letras da UFRGS. Porto Alegre, 2011. p. 168.

BRASIL. Ministério da Educação e Cultura. Lei de Diretrizes e Bases da Educação Nacional. 1996. Disponível em: <ftp://ftp.fnde.gov.br/web/siope/leis/LDB.pdf>. Acesso em: 04 de setembro de 2015.

DI PIERRO, M. C.; JOIA, O.; RIBEIRO, V.M. Visões da Educação de Jovens e Adultos no Brasil. Caderno CEDES, ano XXI, n. 55, novembro 2001.

EISNER apud PATO, P. R. G. História em Quadrinhos: uma abordagem bakhtiniana. 2007. 151 f. Dissertação (Mestrado em Educação). Universidade de Brasília, 2007. p. 83 
V Congresso Brasileiro de Informática na Educação (CBIE 2016)

Anais do XXII Workshop de Informática na Escola (WIE 2016)

HADDAD, S.; DI PIERRO, M.C. Escolarização de Jovens e Adultos. Revista Brasileira de Educação. N. 14, maio/jun/jul/ago. 2000.

MARCHIORO, K. C. O que é a EJA para ti? Os sentidos da EJA na perspectiva discente. 2013. 48f. TCC (Pedagogia). Universidade Federal do Rio Grande do Sul, 2013.

O'REILLY, T. (2005) What Is Web 2.0: Design Patterns and Business Models for theNext Generation of Software. O'Reilly Publishing, 2005.

PLÁ, J.; RAPKIEWICZ, C. E. Perspectivas do uso de Histórias em Quadrinhos digitais: uma análise da pesquisa no Brasil. In: VII CAVA - Congresso Internacional de Ambientes Virtuais de Aprendizagem Adaptativos e Acessivos, 2015.

SANT'ANNA, S. M.L.; STRAMARE, O. A. Uma retomada sobre a educação Jovens e Adultos. Aprendendo com jovens e adultos. Porto Alegre, NIEPE/UFRGS, n. 1, ano 2, dez 2001.

SANTOS, R.; CORRÊA, V.; TOMÉ, M. L. As histórias em quadrinhos na tela do computador. Revista Comunicação Midiática, v.7, n.1, jan./abr. 2012. p. 117

SANTOS, T.; RAPKIEWICZ, C.; SANTOS, V. J. R. M. Análise de serviços online para produção de histórias em quadrinhos. In: XIX TISE - CONFERÊNCIA INTERNACIONAL SOBRE INFORMÁTICA NA EDUCAÇÃO, 2014.

Tirinha de Laerte. Disponível em:

<http://deposito-de-tirinhas.tumblr.com/post/21788003285/uma-r\%C3\%A1pida-pausa-para-umcafezinho-e-de-volta>. Acesso em 16 de setembro de 2014.

TOFFLER, A. A terceira onda. Rio de Janeiro: Record, 2007. 